\title{
Chamadas de Dossiês - Submissão de artigos
}

\section{Pescas Amazônicas}

\section{Coordenadores}

Rubens Elias da Silva - PPGCS/NUPEAM/UFOPA - E-mail: hellazer09@gmail.com Antonio Francisco Perrone Oviedo - CDS/UnB - E-mail: antoniopoviedo@gmail.com David Gibbs McGrath (PPGSND/UFOPA) - E-mail: dgmcgrath52@gmail.com Urbano Lopes da Silva Jr. (INPA) - E-mail: urbanolsjr@gmail.com

Este dossiê deverá compor o volume 2, número 4, da Revista Ciências da Sociedade, ISSN 2594-3987, do Programa de Pós-Graduação Ciências da Sociedade da Universidade Federal do Oeste do Pará, com publicação prevista para outubro/novembro de 2018. O propósito deste dossiê é fomentar a discussão teórica, de campo e de debate acerca dos múltiplos aspectos e abordagens que envolvem o universo da produção pesqueira na Amazônia. A pesca na Amazônia remonta a períodos anteriores à chegada dos europeus, materialmente comprovada com os inúmeros sítios arqueológicos de restos de ostras e peixes, denominados de sambaquis. Até hoje, essa atividade produtiva é um dos mais importantes eixos econômicos de inúmeras comunidades ribeirinhas, varzeiras e do litoral. Associado a isso, as sociedades pesqueiras são espaços onde relações sociais são continuamente reconstruídas, dentro de peculiaridades culturais cujas formas de ser e estar no mundo dão-se no continuum tempo-espaço. Os grandes projetos de governo, amparados no discurso do desenvolvimento nacional e segurança territorial local, tem afetado as populações tradicionais na Amazônia, seu modo de vida e produção econômica: territórios, memórias, sociabilidades. A cabo disso, essas comunidades tem se pautado em lutas sociais interessantes no sentido de que seus direitos sejam respeitados pelo Estado em suas mais diferentes escalas. Sem dúvida, esse processo macrossiociológico tem afetado a esfera da produção da pesca em contextos comunitários, dada as intervenções do governo na construção de hidrelétricas, portos e o estímulo à atividade mineradora. Sendo assim, esse dossiê acolhe estudos que contemplem os mais diversos aspectos sociais no mundo da pesca e de seus atores sociais. Os conflitos socioambientais, as mobilizações políticas, os acordos de pesca, os manejos 
dos recursos pesqueiros daí decorrentes; as crenças, as moralidades, o universo simbólico que permeia e dá sentido às sociabilidades pesqueiras. As contribuições devem ser endereçadas aos e-mails dos dois coordenadores do dossiê acima apresentados até o dia 28 de julho de 2018. As contribuições devem estar conformes as Diretrizes para os Autores constantes da página da Revista Ciências da Sociedade no link: http://www.ufopa.edu.br/portaldeperiodicos/index.php/revistacienciasdasociedade/about /submissions\#authorGuidelines

\title{
Dossiê especial: Afirmação indígena no Baixo Tapajós: território, memória e políticas
}

\author{
Coordenadores (as) \\ Luciana Gonçalves de Carvalho (PPGCS / UFOPA) - E-mail: \\ luciana.gdcarvalho@gmail.com \\ José Maurício Arruti (UNICAMP) - E-mail: jmarruti@gmail.com \\ Solange Gayoso (UFPA) - E-mail: gayososol@yahoo.com.br \\ Gilberto César Lopes Rodrigues (UNICAMP / UFOPA). - E-mail: \\ gilbertocesar@gmail.com
}

Desde 1990 a região do Baixo Tapajós vem registrando crescente número de grupamentos humanos autodeclarados indígenas, até então dados como extintos pelo Estado. A partir da primeira experiência de autoafirmação dos Munduruku de Takuara, a Fundação Nacional do Índio recebeu 64 solicitações de abertura de processo de identificação étnica e delimitação territorial por 13 povos indígenas da região. Em 2000, o Conselho Indígena Tapajós-Arapiuns passou a representar diversas associações indígenas regionais e, em 2017, quatro terras indígenas já contavam com relatório antropológico publicado. No mesmo ano 44 escolas indígenas foram registradas em Santarém, e a Secretaria Especial de Saúde Indígena passou a atender os povos do Baixo Tapajós, conformando amplo e vigoroso processo de afirmação indígena na região. A despeito da crescente visibilidade desse processo, a literatura acadêmica sobre o tema ainda está dispersa. Propomos, assim, este dossiê de pesquisas sobre múltiplas dimensões da afirmação indígena no Baixo Tapajós, as quais são 
de interesse amplamente interdisciplinar, abarcando áreas como história, antropologia, educação, direito, saúde, arqueologia e outras. Este dossiê deverá compor o volume 2, número 5, da Revista Ciências da Sociedade, ISSN 2594-3987, do Programa de Pós-Graduação Ciências da Sociedade da Universidade Federal do Oeste do Pará, com publicação prevista para dezembro de 2018. As contribuições devem ser endereçadas aos e-mails dos dois coordenadores do dossiê acima apresentados até o dia 28 de agosto de 2018. As contribuições devem estar conformes as Diretrizes para os Autores constantes da página da Revista Ciências da Sociedade no link abaixo: http://www.ufopa.edu.br/portaldeperiodicos/index.php/revistacienciasdasociedade/about /submissions\#authorGuideline 